\title{
Trends and patterns of benzodiazepines prescription from 2014 to 2016: A retrospective cross-sectional study in an outpatient setting of tertiary hospital in Malaysia.
}

\author{
Fatin Azzyati Pakururrazi \\ International Islamic University Malaysia \\ Che Suraya Zin \\ International Islamic University Malaysia \\ Helina Abd Halim \\ Hospital Tengku Ampuan Afzan
}

Norny Syafinaz Ab Rahman ( $\nabla$ norny@iium.edu.my )

International Islamic University Malaysia https://orcid.org/0000-0001-8358-0925

\section{Research Article}

Keywords: benzodiazepine, prescribing, trends, patterns, outpatient, Malaysia

Posted Date: February 11th, 2022

DOI: https://doi.org/10.21203/rs.3.rs-1350508/v1

License: (9) (i) This work is licensed under a Creative Commons Attribution 4.0 International License. Read Full License 


\section{Abstract \\ Background}

Despite evidence of their association with adverse drug events and mortality, benzodiazepines are still among the main choice for treating many psychiatric disorders and neurological conditions. To date, there is a meager data on the prescribing trends and patterns of benzodiazepines in Malaysia.

\section{Objective}

This study aimed to investigate the trends and patterns of benzodiazepines prescribing at outpatient hospital setting.

\section{Method}

A retrospective, cross-sectional study was conducted at outpatient pharmacy of a tertiary hospital in Malaysia. Prescriptions for any of seven benzodiazepines (alprazolam, bromazepam, clobazam, clonazepam, diazepam, lorazepam and midazolam) issued from January 2014 until December 2016 were screened and included in this study. Trends and patterns of prescribed benzodiazepines were examined. Descriptive statistics and association between patient characteristics and prescribing patterns were performed using STATA® SE v.13.1 (Stata Corp LP, Texas, USA).

\section{Results}

A total of 5,728 benzodiazepines prescriptions of the seven benzodiazepines were prescribed for 1,943 patients from 2014 to 2016. BZDs were prescribed to $1,013(52.1 \%)$ male with mean age of $46.8 \pm 14.1$ for the whole study population, in which $26.8 \%$ were between $45-54$ years old. About $40 \%$ of benzodiazepines prescribed were classified as short-acting. About $12.6 \%$ reduction in the overall number of benzodiazepine prescriptions from $2014(n=1956)$ to $2016(n=1709)$. Alprazolam was the most frequently prescribed (43.3\%) in 2014, followed by (38.9\%) 2015 and (36.8\%) 2016. Approximately, 69.64\% $(n=6,218)$ of benzodiazepines were prescribed for a duration of 15 to 30 days, while $57.29 \%(n=5,115)$ of benzodiazepines were prescribed with fixed dosing schedule.

\section{Conclusion}

Overall benzodiazepine prescription shows a decreasing trend from 2014 to 2016 . Alprazolam, the short-acting benzodiazepine was the most frequently prescribed in hospital outpatient setting in Malaysia.

\section{Introduction}

Benzodiazepines are commonly prescribed for psychiatric disorder. Mother' $s L i \leq$ Helpers' and Sleepers' are among many nick names bestowed upon this class of drugs, to describe benzodiazepines. As it possess sedative, hypnotics, anxiolytics and muscle relaxants properties; it is often medically used to treat insomnia, panic disorder, relieve stress and seizures among other [1]. BZD were widely noted as breakthrough drugs, which were believed to surpass its predecessor's effectiveness - the barbiturates.

Thus when it was marketed in the 1960, it became the most commercially successful drug at that time. They were thought to be a solution by many prescribers because they acted effectively on anxiety, mixed anxiety depression, and other nonspecific physical complaints while at the same time being comparatively safe [2, 3]. BZDs are also often used in conjunction with other psychotropic drugs. For example, the combination of BZD and antidepressant led to greater response and to less drop-out than antidepressant alone in the acute phase treatment of depression [4]. 
However, the joy of prescribing it in abundance has taken its toll. Albeit benzodiazepine has legitimate indication, it also has its risk and harm that should not be overseen. After society discovered BZDs are taxed with addictiveness, it remains unclear how addictive they were when compared to other related list of psychoactive drugs [2]. While short-term uses of these medications are generally safe and effective, the long term use of benzodiazepines is debatable, chiefly because of the potential of dependence, withdrawal and tolerance [5]. When use for extended period of time, they may lead to problems associated with discontinuation and withdrawal symptoms and also abuse [6, 7]. Benzodiazepine use is also associated with adverse drug events such as dementia and psychomotor impairments, which lead to premature death [8]. Known risk factors for benzodiazepine-related adverse events include lung disease, substance use, and vulnerability to fracture [9]. Although causality has not been definitively determined, strong associations between benzodiazepine prescribing and mortality have been described in younger population [8]. Benzodiazepines are drugs that should be used for very short time, at most for a few days or weeks in selected patients, carefully monitored, and stopped as soon as possible, as recommended in their summary of product characteristics and in all international recommendation [11]. The risk-benefit balance of using BZD in the long term is accordingly to be negative. BZD is commonly prescribed for short-term duration (1-4 weeks) to reduce the risk of dependence and withdrawal [11]. A WHO guideline for traumatic stress in non-specialized settings suggests that, when psychotherapy is not practical, short-term treatment with BZD may be considered [12]. Other guidelines also make similar favourable mentions [13, 14].

The Committee on the Review of Medicines in the United Kingdom, for example, has issued a warning regarding the regular long-term use of benzodiazepine and expresses their concern on the high number of patients with repeat prescriptions for an unusually long period [15]. The primary basis of the worry seems to be about the risk of normal and excessive usage of benzodiazepine, the tolerance level, dependence potential and the abuse liability of benzodiazepines. Today, the dispute encircling the use of benzodiazepines is still open for debate. Benzodiazepine prescribing trends may vary in each country, but their long-term usage is usually seen and treated as the norm in many.

Quantifying benzodiazepines usage in populations helps to reaffirm the current prescribing practices and pinpoint the existence of problematic consumption that could be prophetical for primary adverse outcomes. While several developed countries have established a nationwide register of patient's data to enable them to conduct a study not only on benzodiazepines but also other medications related to current pharmacoepidemiology issues, scant information is available about the nature of benzodiazepines prescribing in Malaysia compared to other countries. Due to this limitation, the data on the trends and patterns of benzodiazepines prescriptions and its use in Malaysia are still limited. This study aimed to investigate the trends and patterns of benzodiazepines prescribing at the out-patient setting of Malaysian public hospital.

\section{Ethics Approval}

Approval to conduct this study was granted by the Medical Research Ethical Committee (MREC), Ministry of Health Malaysia (Date: 11th October 2016 / Registration no: NMRR-16-1742-28839).

\section{Method}

\section{Study design and data source}

This retrospective, cross-sectional study was conducted at the outpatient pharmacy of a public tertiary hospital in Malaysia. This study has been granted ethical approval from the Medical Research Ethical Committee (MREC), Ministry of Health Malaysia. It was carried out with the approved of the Medical Research Ethics Committee (MREC), Ministry of Health Malaysia (NMRR-16-1742-28839). The data on patient information were de-identified and only aggregate results were reported. There was no direct patients' involvement in this study that did not require informed consent from patients.

Prescriptions for seven benzodiazepines (alprazolam, bromazepam, clobazam, clonazepam, diazepam, lorazepam and midazolam) issued from January 2014 until December 2016 was identified together with these inclusion criteria; having at least one type of benzodiazepine prescribed in a prescription, the prescribed benzodiazepines must be in oral formulation only 
for patient's aged 18 years old and above. Information extracted from the prescriptions includes patient age and gender, name of medication, dosage form, dose, strength, frequency, duration, the amount supplied, diagnosis, and issuing department.

Benzodiazepines were categorized according to the type, ATC code, duration of action and onset of action. Benzodiazepines were described by the ATC code as N05BA (anxiolytics: alprazolam, bromazepam, clobazam, diazepam, lorazepam), N05CD (hypnotics/sedatives: midazolam), and N03AE01 (antiepileptic: clonazepam). Based on duration of action, benzodiazepines are classified into three groups; short-acting ( $\leq 12$ hours: alprazolam and midazolam), intermediate-acting (12-24 hours: bromazepam, clonazepam and lorazepam) and long-acting ( $\geq 24$ hours: diazepam and clobazam). Based on the onset of action, benzodiazepines are divided into two categories; rapid action (within 15 minutes: diazepam and midazolam) and intermediate action (from 15 minutes to 30 minutes: alprazolam, bromazepam, clobazam, clonazepam and lorazepam).

\section{Calculation for the defined daily dose (DDD)}

The number of DDDs consumed is calculated according to the following formula by Truter, Wiseman, \& Kotze, (1996). The calculation of DDD was done for each patient starting from the first day they received their prescription until the last day of our study frame.

\section{Benzodiazepine prescribing patterns}

Fundamentally, the patterns of benzodiazepines prescribed in the study are acquired from the information of the prescription slips. The applied patterns analysis is not corresponding to the number of patients or the number of prescriptions since one patient, or one prescription may contain more than one benzodiazepines. Moreover, each prescribing patterns are consistently following the number of dispensation, not the number of patients or prescriptions.

\section{Data analysis}

The patients and prescriptions were measured monthly and annually. Prescribing trends and patterns (ATC classification, duration of action and onset of action) for each type of benzodiazepine were also analysed and presented as number, percentage and DDD/1000/day. Descriptive statistics and association between patient characteristics and prescribing patterns were performed using STATA® SE v.13.1 (Stata Corp LP, Texas, USA).

\section{Results}

\section{Number of benzodiazepine users}

A total of 1,943 patients (52.14\% male) had received 5,728 benzodiazepines prescriptions from 2014 to 2016 (Table 1). The mean age of patients received benzodiazepines was $46.8 \pm 14.1$ years, and it ranges from 18 to 93 years old. Out of six age ranks, patients aged $45-54$ years recorded the highest percentage (26.81\%), followed by 35-44 (19.3\%), 25-34 (18.17\%), 55$64(15.29 \%), 65$ and above (11.12\%) and 18-24 (7.51\%). 
Table 1

Patients' Characteristics

\begin{tabular}{|c|c|c|c|c|}
\hline \multirow[t]{2}{*}{ Characteristicss } & \multicolumn{2}{|c|}{ Patients $(n=1,943)$} & \multicolumn{2}{|c|}{ Prescriptions $(n=5,728)$} \\
\hline & $\mathrm{n}$ & $\%$ & $\mathrm{n}$ & $\%$ \\
\hline \multicolumn{5}{|l|}{ Sex } \\
\hline Male & 1,013 & 52.14 & 2,945 & 51.41 \\
\hline Female & 930 & 47.86 & 2,783 & 48.59 \\
\hline \multicolumn{5}{|l|}{ Race } \\
\hline Malay & 1,186 & 61.04 & 3,252 & 56.77 \\
\hline Chinese & 585 & 30.11 & 2,148 & 37.50 \\
\hline Indian & 146 & 7.51 & 246 & 4.29 \\
\hline Others & 26 & 1.34 & 82 & 1.43 \\
\hline \multicolumn{5}{|l|}{ Age } \\
\hline \multicolumn{5}{|l|}{ Mean (SD) : } \\
\hline \multicolumn{5}{|l|}{$46.8(14.1)$} \\
\hline \multicolumn{5}{|l|}{ Range : 18-93 } \\
\hline \multicolumn{5}{|l|}{ Age group } \\
\hline $18-24$ & 146 & 7.51 & 314 & 5.48 \\
\hline $25-34$ & 353 & 18.17 & 945 & 16.50 \\
\hline $35-44$ & 375 & 19.30 & 1,195 & 20.86 \\
\hline $45-54$ & 521 & 26.81 & 1,685 & 29.42 \\
\hline $55-64$ & 297 & 15.29 & 886 & 15.47 \\
\hline $65 \geq$ & 216 & 11.12 & 668 & 11.66 \\
\hline NA & 35 & 1.8 & 35 & 0.61 \\
\hline
\end{tabular}

\section{Monthly number of benzodiazepine prescriptions}

Figure 1 showed approximately 5.5\% increased of prescriptions from $2014(n=1,956)$ to $2015(n=2,063)$, but later a decreasing trend of $34.3 \%$ from 2015 to 2016 ( $n=1,709)$. A line chart with a trendline was constructed to see the trends over months of the study duration, which witnessed an increase in trend in 2014 and decreasing trends in both 2015 and 2016. In general, the study observed a drop of 12.6\% number of prescriptions from 2014 to 2016.

\section{Benzodiazepine prescribing patterns}

The study discovers that from 5,728 prescriptions, there were 8,929 benzodiazepines issued throughout the three years. The analysis of prescribing patterns is described in Table 2 in regards to the number of benzodiazepines dispensation; $n=8929$. In regards to the duration of supply for benzodiazepines, the study recognised there are 79 types of duration available in the data. The benzodiazepines day supply ranges as one day to a maximum of 240 days (mean 34.43 days). Those durations were then grouped into five types (1-7 days, $8-14$ days, $15-30$ days, $31-60$ days and $>60$ days), as listed in Table 2 . Throughout the analysis of data, it was found that 16 types of dosing schedule involved in the study however, the dosing schedule is further categorised into two types; fixed schedule and as needed schedule (Table 2). 
Table 2

Patterns of Benzodiazepines Prescribed Based on Prescription

\begin{tabular}{|c|c|c|c|c|c|}
\hline Patterns $(n=8929)$ & $\begin{array}{l}2014 \\
\text { (n) }\end{array}$ & $\begin{array}{l}2015 \\
\text { (n) }\end{array}$ & $\begin{array}{l}2016 \\
\text { (n) }\end{array}$ & Frequency (n) & Percentage (\%) \\
\hline \multicolumn{6}{|l|}{ Types of Benzodiazepines } \\
\hline Alprazolam & 1272 & 1255 & 1015 & 3,542 & 39.67 \\
\hline Bromazepam & 20 & 24 & 24 & 68 & 0.76 \\
\hline Clobazam & 3 & 6 & 0 & 9 & 0.1 \\
\hline Clonazepam & 415 & 604 & 511 & 1,530 & 17.14 \\
\hline Diazepam & 543 & 662 & 646 & 1,851 & 20.73 \\
\hline Lorazepam & 672 & 657 & 551 & 1,880 & 21.05 \\
\hline Midazolam & 16 & 21 & 12 & 49 & 0.55 \\
\hline \multicolumn{6}{|c|}{ Class of Benzodiazepines by ATC Code } \\
\hline Antiepileptic (N03AE) & 415 & 604 & 511 & 1,530 & 17.14 \\
\hline Anxiolytic (N05BA) & 2510 & 2604 & 2236 & 7,350 & 82.32 \\
\hline Hypnotic / Sedative (N05CD) & 16 & 21 & 12 & 49 & 0.55 \\
\hline \multicolumn{6}{|c|}{ Class of Benzodiazepines by Duration of Action } \\
\hline Short-Acting (<12 hr) & 1288 & 1276 & 1027 & 3,591 & 40.22 \\
\hline Intermediate-Acting (12-24 hr) & 1107 & 1285 & 1086 & 3,478 & 38.95 \\
\hline Long-Acting ( $\geq 24$ hr ) & 546 & 668 & 646 & 1,860 & 20.83 \\
\hline \multicolumn{6}{|c|}{ Class of Benzodiazepines by Onset of Action } \\
\hline Rapid action (within 15 minutes) & 1231 & 1340 & 1209 & 3,780 & 42.33 \\
\hline \multicolumn{6}{|l|}{ (15-30 minutes) } \\
\hline \multicolumn{6}{|l|}{ Dosing Schedule } \\
\hline Fixed Dosing & 1661 & 1866 & 1588 & 5,115 & 57.29 \\
\hline As Needed Dosing & 1280 & 1363 & 1171 & 3,814 & 42.71 \\
\hline \multicolumn{6}{|l|}{ Duration of Supply } \\
\hline $1-7$ days & 340 & 376 & 300 & 1,016 & 11.38 \\
\hline $8-14$ days & 365 & 289 & 339 & 993 & 11.12 \\
\hline $15-30$ days & 2056 & 2274 & 1888 & 6,218 & 69.64 \\
\hline $31-60$ days & 159 & 252 & 222 & 633 & 7.09 \\
\hline$>60$ days & 21 & 38 & 10 & 69 & 0.77 \\
\hline \multicolumn{6}{|l|}{ Concurrent Medications $(n=17,106)$} \\
\hline Antidepressant & 1287 & 1169 & 1013 & 3,469 & 20.28 \\
\hline Antipsychotic & 757 & 857 & 809 & 2,423 & 14.16 \\
\hline
\end{tabular}




\begin{tabular}{|llllll|}
\hline Patterns $(\mathbf{n}=\mathbf{8 9 2 9})$ & $\begin{array}{l}\mathbf{2 0 1 4} \\
\mathbf{( n )}\end{array}$ & $\begin{array}{l}\mathbf{2 0 1 5} \\
\mathbf{( n )}\end{array}$ & $\begin{array}{l}\mathbf{2 0 1 6} \\
(\mathbf{n})\end{array}$ & Frequency (n) & Percentage (\%) \\
\hline Antiparkinson & 293 & 361 & 291 & 945 & 5.52 \\
\hline Antiepilepsy & 219 & 283 & 279 & 781 & 4.57 \\
\hline Analgesic & 6 & 15 & 8 & 29 & 0.17 \\
\hline Others & 162 & 194 & 174 & 530 & 3.1 \\
\hline Diagnosis & & & & & \\
\hline Psychiatric Disorder & 2664 & 2889 & 2528 & 8,081 & 90.5 \\
\hline Non-Psychiatric Disorder & 277 & 340 & 231 & 848 & 9.5 \\
\hline Issuing department & & & & & \\
\hline Psychiatry Department & 2466 & 2586 & 2228 & 7,280 & 81.53 \\
\hline Non-Psychiatry Department & 475 & 643 & 531 & 1,649 & 18.47 \\
\hline
\end{tabular}

Out of seven types of benzodiazepines included in the study, alprazolam has the most significant percentage (39.67\%), with 3,542 dispensations, followed by lorazepam (21.05\%), diazepam (20.73\%), clonazepam (17.14\%), bromazepam (0.76\%), midazolam $(0.55 \%)$ and lastly clobazam $(0.1 \%)$. Alprazolam remained the highest benzodiazepines prescribed from the outpatient pharmacy throughout the study duration. Based on the ATC classification, benzodiazepines that fall under anxiolytics are the highest prescribed by the prescribers since 2014. The result also revealed that short-acting benzodiazepines are the leading choice $(n=3591,40.22 \%)$ in terms of frequency $(n)$ and percentages $(\%)$ for three years; compared to longacting $(n=1,860,20.83 \%)$ and intermediate-acting benzodiazepines $(n=3,478,38.95 \%)$. However, the pattern of prescribing changed from short-acting benzodiazepines in 2014, towards intermediate-acting in recent years (2015 and 2016).

The analysis also indicates that in view on the onset of action, prescribers frequently prescribed intermediate-action benzodiazepines (57.67\%) rather than rapid-action (42.33\%) benzodiazepines. This pattern continues from 2014 till 2016. Throughout the study period, there were no changes in the patterns of dosing schedule, duration of supply, concurrent medications, diagnosis and issuing department. All three years saw fixed dosing as the most frequent dosing schedule, 15-30 days was the most common duration of supply, antidepressant as the most common type of medication concurrently prescribed with benzodiazepines, a psychiatric disorder was the highest diagnosis written for benzodiazepines patient and psychiatry department mainly prescribed BZD in the study.

\section{Prescribing Trends of Benzodiazepines Based on Defined Daily Dose (DDD)}

Table 3 presents the trends of benzodiazepines in miligrams and DDD for year 2014, 2015 and 2016. In 2014, 117,942.5mg of benzodiazepines was dispensed, and the number increased $20 \%$ to $141,588.5 \mathrm{mg}$ in 2015 . However, a $10 \%$ reduction was seen in $2016(126,676.75 \mathrm{mg})$, making a total of $386,208 \mathrm{mg}$ of benzodiazepines dispensed throughout the study period. There was a surge of $6 \%$ in yearly defined daily dose (DDD/1000 patients/year) from 2014 to 2015 before it came down $15 \%$ in the subsequent year. Meanwhile, a decreasing trend was noticed in regards to the DDD/1000 patients/day in which $1.9 \%$ and $7.25 \%$ decrease was observed in 2015 and 2016, respectively. 
Table 3

Trends of Benzodiazepines in Milligrams and Defined Daily Dose

\begin{tabular}{|lllll|}
\hline Amount/Year & $\mathbf{2 0 1 4}$ & $\mathbf{2 0 1 5}$ & $\mathbf{2 0 1 6}$ & Total \\
\hline Amount of benzodiazepines dispensed (mg) & $117,942.5$ & $141,588.5$ & $126,676.75$ & 386,208 \\
\hline DDD/1000 patients/day (DDD) & 0.23405 & 0.22956 & 0.21291 & 0.67652 \\
\hline DDD/1000 patients/year (DDD) & 86.664 & 92.226 & 77.648 & 256.538 \\
\hline
\end{tabular}

\section{The Association between Gender, Age Group and Type of Benzodiazepines}

Table 4 concludes the association of benzodiazepines types and patient's age group. It was noted that patient aged 45-54 years are the most common to received benzodiazepines, especially alprazolam $(n=1,149,12.87 \%)$. In addition, it also found that those who were prescribed with alprazolam were significantly more likely to be male $(P<0.001), 21.63 \%$. The $P$-value showed result lower than 0.001 , which indicates a strong association between patient's age group and the selection of benzodiazepines' type. 
Association Between Gender, Age Group and Types of Benzodiazepines

\begin{tabular}{|c|c|c|c|c|c|c|c|c|}
\hline \multirow[b]{2}{*}{$\begin{array}{l}\text { Age } \\
\text { Group }\end{array}$} & \multicolumn{8}{|c|}{ Types of Benzodiazepines n (\%) } \\
\hline & Alprazolam & Bromazepam & Clobazam & Clonazepam & Diazepam & Lorazepam & Midazolam & Total \\
\hline \multirow[t]{2}{*}{$18-24$} & 137 & - & - & 86 & 100 & 109 & 4 & 436 \\
\hline & $(1.53)$ & - & - & $(0.96)$ & $(1.12)$ & $(1.22)$ & $(0.04)$ & $(4.88)$ \\
\hline \multirow[t]{2}{*}{$25-34$} & 451 & - & - & 130 & 407 & 251 & 12 & 1,251 \\
\hline & $(5.05)$ & - & - & $(1.46)$ & $(4.56)$ & $(2.81)$ & $(0.13)$ & $(14.01)$ \\
\hline \multirow[t]{2}{*}{$35-44$} & 640 & - & 1 & 277 & 407 & 374 & 12 & 1,711 \\
\hline & $(7.17)$ & - & $(0.01)$ & $(3.1)$ & $(4.56)$ & $(4.19)$ & $(0.13)$ & $(19.16)$ \\
\hline \multirow[t]{2}{*}{$45-54$} & 1,149 & 24 & 8 & 430 & 526 & 505 & 9 & 2,651 \\
\hline & (12.87) & $(0.27)$ & $(0.09)$ & $(4.82)$ & $(5.89)$ & $(5.66)$ & $(0.1)$ & $(29.69)$ \\
\hline \multirow[t]{2}{*}{$55-64$} & 669 & 19 & - & 369 & 286 & 292 & 7 & 1,642 \\
\hline & (7.49) & $(0.21)$ & - & $(4.13)$ & (3.2) & (3.27) & $(0.08)$ & (18.39) \\
\hline \multirow[t]{2}{*}{$\geq 65$} & 467 & 25 & - & 233 & 123 & 336 & 5 & 1,189 \\
\hline & $(5.23)$ & $(0.28)$ & - & $(2.61)$ & $(1.38)$ & $(3.76)$ & $(0.06)$ & $(13.32)$ \\
\hline \multirow[t]{2}{*}{ Missing } & 29 & - & - & 5 & 2 & 13 & - & 49 \\
\hline & $(0.32)$ & - & - & $(0.06)$ & $(0.02)$ & $(0.15)$ & - & $(0.55)$ \\
\hline \multirow[t]{2}{*}{ Total } & 3,542 & 68 & 9 & 1,530 & 1,851 & 1,880 & 49 & 8,929 \\
\hline & (39.67) & $(0.76)$ & $(0.1)$ & (17.14) & $(20.73)$ & $(21.05)$ & $(0.55)$ & (100) \\
\hline $\begin{array}{l}\text { Pearson } \\
\text { chi- } \\
\text { square }\end{array}$ & & & & 399.4975 & & & & \\
\hline P-value & & & & $p<0.001$ & & & & \\
\hline Gender & 1,611 & 12 & 8 & 690 & 834 & 1,134 & 38 & 4,327 \\
\hline \multirow[t]{2}{*}{ Female } & (18.04) & $(0.13)$ & $(0.09)$ & $(7.73)$ & $(9.34)$ & $(12.7)$ & $(0.43)$ & $(48.46)$ \\
\hline & 1,931 & 56 & 1 & 840 & 1,017 & 746 & 11 & 4,602 \\
\hline \multirow[t]{2}{*}{ Male } & (21.63) & $(0.63)$ & $(0.01)$ & $(9.41)$ & (11.39) & (8.35) & $(0.12)$ & $(51.54)$ \\
\hline & 3,542 & 68 & 9 & 1,530 & 1,851 & 1,880 & 49 & 8,929 \\
\hline Total & (39.67) & $(0.76)$ & $(0.1)$ & (17.14) & (20.73) & $(21.05)$ & $(0.55)$ & $(100)$ \\
\hline $\begin{array}{l}\text { Pearson } \\
\text { chi- } \\
\text { square }\end{array}$ & 182.281 & & & & & & & \\
\hline P-value & $p<0.001$ & & & & & & & \\
\hline
\end{tabular}

The Association between Gender, Age Group and Duration of action of Benzodiazepines 
Short-acting benzodiazepines are the most commonly prescribed benzodiazepines among male patients $(n=1,942,21.75 \%)$ and among patient aged $45-54$ years old $(n=1,158,12.97 \%$ ) (Table 5). Pearson chi-square analysis shows a significant relationship $(P<0.001)$ between gender, age group and the duration of action of benzodiazepines.

Table 5

Association Between Gender, Age Group and Benzodiazepines Duration of Action

\begin{tabular}{|c|c|c|c|}
\hline \multirow[t]{2}{*}{ Age Group } & \multicolumn{3}{|l|}{ Duration of Action n (\%) } \\
\hline & Short-Acting ( $<12 \mathrm{hr})$ & Intermediate-Acting (12-24 hr) & Long-Acting ( $\geq 24 \mathrm{hr}$ ) \\
\hline \multirow[t]{2}{*}{$18-24$} & 141 & 195 & 100 \\
\hline & $(1.58)$ & $(2.18)$ & $(1.12)$ \\
\hline \multirow[t]{2}{*}{$25-34$} & 463 & 381 & 407 \\
\hline & $(5.19)$ & $(4.27)$ & $(4.56)$ \\
\hline \multirow[t]{2}{*}{$35-44$} & 652 & 651 & 408 \\
\hline & $(7.3)$ & $(7.29)$ & $(4.57)$ \\
\hline \multirow[t]{2}{*}{$45-54$} & 1,158 & 959 & 534 \\
\hline & (12.97) & $(10.74)$ & $(5.98)$ \\
\hline \multirow[t]{2}{*}{$55-64$} & 676 & 680 & 286 \\
\hline & $(7.57)$ & $(7.62)$ & $(3.2)$ \\
\hline \multirow[t]{2}{*}{$\geq 65$} & 472 & 594 & 123 \\
\hline & $(5.29)$ & $(6.65)$ & $(1.38)$ \\
\hline \multirow[t]{2}{*}{ Missing } & 29 & 18 & 2 \\
\hline & $(0.32)$ & $(0.2)$ & $(0.02)$ \\
\hline \multirow[t]{2}{*}{ Total } & 3,591 & 3,478 & 1,860 \\
\hline & $(40.22)$ & $(38.95)$ & $(20.83)$ \\
\hline Pearson chi-square & & 266.4689 & \\
\hline P-value & & $p<0.001$ & \\
\hline \multicolumn{4}{|l|}{ Gender } \\
\hline \multirow[t]{2}{*}{ Female } & 1,649 & 1,836 & 842 \\
\hline & $(18.47)$ & $(21)$ & $(9.43)$ \\
\hline \multirow[t]{2}{*}{ Male } & 1,942 & 1,642 & 1,018 \\
\hline & $(21.75)$ & (18.39) & $(11.4)$ \\
\hline \multirow[t]{2}{*}{ Total } & 3,591 & 3,478 & 49 \\
\hline & $(40.22)$ & (38.95) & $(0.55)$ \\
\hline Pearson chi-square & 42.9528 & & \\
\hline P-value & $p<0.001$ & & \\
\hline
\end{tabular}

\section{Discussion}


The National Health and Morbidity Survey (NHMS) 2015 reported that there is an increasing trend in the prevalence of mental health problems among adults. The prevalence of approximately escalates threefold from $10.7 \%$ in 1996 to $29.2 \%$ in 2015 [17]. Naturally, in keeping with the increasing cases, we would expect a similar increase in the prescribing trends of psychotropic drugs, especially benzodiazepines. However, the Malaysian Statistics on Medicines (MSOM) 2015 reported a drop of 22\% in the overall usage of benzodiazepines; from 1.313 DDD/1000 patients/day in 2011 to 1.024 DDD/1000 patients/day in 2014 [18]. In summary, our study showed similar decreasing trends on the number of patients receiving benzodiazepines, the number of benzodiazepines prescriptions and also the DDD of benzodiazepines in comparison to the MSOM 2015. However, the prescribing trends of this study are comparatively low in contrast to other research outside Malaysia that was done during the same study period. Prior research in Australia also showed decreasing trends in benzodiazepines utilisation, though the overall benzodiazepines consumption remained relatively high. There were a total of 27.7 , and 20.8 DDD/1000 patients/day of benzodiazepines dispensed in 1992 and 2011, while 14.2 DDD/1000 people/day were dispensed between 2013 to 2016, respectively $[19,20]$. Furthermore, the yearly study in Finland also documented a declining trend from 15.7, 14.69 and 13.6 DDD/1000 people/day in 2014, 2015 and 2016, respectively [21].

The overall reduction trends in the number of prescriptions and the benzodiazepines defined daily dose is likely due to strict governmental enforcement and establishment of levels of authority in relation to prescriber's category that prevented the widespread usage and over-prescribing of benzodiazepines in government healthcare facilities. The law and regulations covering the benzodiazepines have also prevented 'doctor shopping' and self-prescribes by patients via community pharmacies or illegal online stores since a prescription is compulsory for the purchasing of benzodiazepines. Moreover, there are also public educations of benzodiazepines potential adverse effects in this country. The reduction of trends can also be attributed to the changes in the price of benzodiazepines in the market throughout the year of study. However, since the study did not include the estimation of sales and procurement data, we cannot confidently associate to this factor.

Consequently, the prescribing trends of benzodiazepines can be seen as a result of multimodal influence including from patient, prescriber and local prescribing practice [22-25]. Verily, the use of benzodiazepines in each region varies greatly, depending on the nation, legislature and local practice. Benzodiazepine was not uncommon in Japan and was found in up to $11.9 \%$ of annual prescriptions in a tertiary care hospital [26]. In Hong Kong and Beijing, benzodiazepine prescription was found in up to $29.9 \%$ of prescriptions to 505 outpatients [25,27]. In North India, half of the psychotic and bipolar patients and two-third of depressive patients of the study group received benzodiazepines [28].

On the other hand, Kaufmann et al., (2016), Tu, Mamdani, Hux, \& Tu, (2001) and Cunningham, Hanley, \& Morgan (2010) reported that the elderly (aged 65 and above) to be the majority in using BZDs [29-31]. Benzodiazepines are more dominant in female, and its use is increased steadily with age, which indicates the elderly are usually the highest receiver $[18,30,32-37]$.

Nevertheless, there is a significant similarity in view to the age group of benzodiazepines patient of this study compared with other established studies. Most of the patient that received benzodiazepines falls under the age of 45 years old and above. The lower rates of benzodiazepines prescribing to the elderly patients ( 65 years old and above) receiving benzodiazepines compared to other age groups in this study can be contributed to the practice guidelines which strongly recommended initiation of non-pharmacologic approaches and then the use of antidepressant over benzodiazepines as first-line treatment for insomnia and anxiety among the elderly [38]. Conversely, this finding provides evidence of the prescriber's adherence to the guidelines.

Alprazolam remained as the most frequent benzodiazepines prescribed to the study cohort throughout the study period. In Malaysia, alprazolam is available in three strength of tablet $(0.25 \mathrm{mg}, 0.5 \mathrm{mg}$ and $1 \mathrm{mg})$ while other benzodiazepines only have one strength of tablet. This could be one of the reasons that appointed them as the golden choice for prescribers. Variable options in tablet strength ensure convenience in dose tapering and high suitability for patient compliance. Alprazolam was observed in our study as the most prescribed benzodiazepines in which it is consistent with the findings in the previous works of literature [37, 39-40]. Though the choice of prescribing alprazolam seems to have its legitimacy, it is essential to note that, while alprazolam has a short duration of action, it has higher toxicity in overdose, and has been reported to be associated with fatality in relative to other benzodiazepines [40]. 
The choice of benzodiazepines frequently prescribed in the current study differs from other studies, which have been published previously. For instance, Sundaran et al., (2019), Grover et al. (2012) and Tor et al. (2011) found that the most commonly prescribed benzodiazepines were lorazepam and clonazepam [23, 28, 36]. A 20 years (1992-2011) study on benzodiazepines trends in Australia found that surprisingly, temazepam is the most dispensed benzodiazepines in the country, accounting to $35 \%$ of the whole prescriptions studied. Meanwhile, previous studies had reported diazepam as the most frequently prescribed [20, 41-43]. Although clonazepam and diazepam both are listed as prescriber category B (ie. a prescription item) by the Ministry of Health Malaysia, they are not as frequently prescribed compared to other benzodiazepines. This gives rise to a question of whether the prescriber who prescribed alprazolam correctly fulfill the authorisation level provided. Therefore, we found that the differences in the choice of benzodiazepines in each country are assumed to be due to availability factors and differences in clinical practice.

Short-acting benzodiazepines such as alprazolam and midazolam are an excellent choice for acute relief of anxiety, panic attack, and stabilising mood. This is because they are rapidly absorbed, thus takes effect more quickly, and their therapeutic effect did not last too long to affect daily life routine. A recent study mentioned that short-acting benzodiazepines are recommended over long-acting benzodiazepines to alleviate the risk of dependency [44]. Furthermore, previous studies also recorded the long-acting formulations of benzodiazepines such as diazepam and lorazepam are the dominant choices among the prescribers [35-36, 42]. Both the usage of short and long-acting benzodiazepines is recommended in many guidelines for different medical conditions. Due to the insufficient data to support the reason behind the selection of short or long-acting formulation, the study could not justify such preference.

In the present study, findings showed that the male patient is more likely to be prescribed with anxiolytics, short-acting benzodiazepines and alprazolam. Additionally, looking into the duration of supply patterns, male patients are more likely to be dispensed with duration of 15 to 30 days, and the benzodiazepines were ordered with a fixed dosing schedule. The significantly higher odds of male prescribed with benzodiazepines can be seen in another study as well [45]. There is a statistically significant association seen between the tested variables and majority of patients aged 45-54 years old are very likely to receive anxiolytics, short-acting benzodiazepines, the duration of supply and the dosing schedule. Referring to Jessell et al., (2020) and Bushnell et al., (2017), they had described that patient aged 40 years and above and diagnosed with psychiatric disorders are more likely to be dispensed with benzodiazepines, especially if the prescribers are from the psychiatric department, compared with if other departments manage the patient [44-45]. The high occurrence of benzodiazepines prescriptions in older patients may reflect an association between age, the prevalence of psychiatric illness and longer benzodiazepine prescriptions. The combination of the above may contribute to adverse clinical outcomes that frequently associated with benzodiazepines in the elderly, such as the risk of fall, dose-dependency and mortality.

\section{Study Limitations}

Our study has several limitations. We focused only on the prescription data, and this necessarily does not reflect the exact clinical situation. Moreover, our study was limited to one tertiary care, which may or may not reflect the national trends. Furthermore, the prescription data may not include the indication for initiating treatments since the principal diagnosis written on the prescription does not necessarily refer to the primary indication of each benzodiazepine. Due to compliance problems, some of the prescribed drugs may not have been consumed according to what has been ordered in the prescription. Hence, we can only get the total number of benzodiazepine prescribed to the patient, but not the total number of benzodiazepine consumed.

Besides, there is insufficient data to support the status of the patient; whether they are naïve or chronic benzodiazepine user. The study is unable to determine that the first appearance of the patient in the data collected during the study period is the first dispensation of benzodiazepine to the patient or the first time the patient takes the medication. The patient may have defaulted follow up for a few weeks or months before the start of the study. A comprehensive comparison with a longer duration of retrospective years was limited due to lack of data availability.

Page $12 / 16$ 


\section{Conclusions}

The overall benzodiazepines prescribing trends in Malaysia was low throughout the three retrospective years compared to the increasing psychiatric problems in the country. As a whole, it is believed that this study provides sufficient data that could be a jump start for future work. The trends and patterns described in the study allow for an estimation of the prevalence of the medical condition, providing the basis of risk assessment and pharmacovigilance and also set a standard for future reference of trends and patterns of benzodiazepines in Malaysia. A comprehensive analysis as the current study on the prescribing trends and patterns of benzodiazepines and their association with patient's demographic characteristics may offer valuable information on future policy and planning of the public health measures concerning benzodiazepines.

\section{Declarations}

\section{Statements and Declarations}

This study was funded by the Research Initiative Grant Scheme (RIGS) IIUM (RIGS15-091-0091).

\section{Competing Interests}

The authors have no relevant financial or non-financial interests to disclose.

\section{Author Contributions}

NSAR and CSZ contributed to the study conception and design. Material preparation, data collection and analysis were performed by FAP and NSAR. The first draft of the manuscript was written by FAP and was revised and refined by NSAR. All authors commented on the revised versions of the manuscript. All authors read and approved the final manuscript.

\section{Data availability}

The datasets generated during and/or analysed during the current study are available from the corresponding author on reasonable request.

\section{Consent to participate}

This study did not involve direct communication or participation with subjects or patients. Research only involved data of patients and medications retrieved from prescriptions and record books. Thus, patients consent is not require in this study.

\section{References}

1. Khawaja MR, Majeed A, Malik F, Merchant KA, Maqsood M, Malik R, ... Naqvi H. Prescription pattern of benzodiazepines for inpatients at a tertiary care university hospital in Pakistan. J Pak Med Assoc. 2005;55(6):259-63.

2. Shorter E. (2005). A Historical Dictionary OF Psychiatry. Oxford University Press (1st Editio). New York: Oxford University Press, Inc.

3. Lader M. Benzodiazepines revisited-will we ever learn? Addiction. 2011 Dec;106(12):2086-109. doi: 10.1111/j.13600443.2011.03563.x. Epub 2011 Oct 17. PMID: 21714826.

4. Furukawa TA, Streiner D, Young LT, Kinoshita Y. Antidepressants plus benzodiazepines for major depression. Cochrane Database of Systematic Reviews 2001, Issue 3. Art. No.: CD001026. DOI:10.1002/14651858.CD001026.

5. Rivas-Vazquez RA. Benzodiazepines in contemporary clinical practice. Prof Psychology: Res Pract. 2003;34(3):324-8. Https://doi.org/10.1037/0735-7028.34.3.324.

6. Voshaar R, Couvee J, Van Balkom A, Mulder P, Zitman F. Strategies for discontinuing long-term benzodiazepine use: Metaanalysis. Br J Psychiatry. 2006;189(3):213-20. doi:10.1192/bjp.189.3.213. 
7. Rickels K, Schweizer E, Case WG, Greenblatt DJ. Long-term therapeutic use of benzodiazepines. I. Effects of abrupt discontinuation. Arch Gen Psychiatry. 1990;47:899-907.

8. Weich S, Pearce HL, Croft P, Singh S, Crome I, Bashford J, Frisher M. Effect of anxiolytic and hypnotic drug prescriptions on mortality hazards: retrospective cohort study. BMJ. 2014;348(March):1-12. Https://doi.org/10.1136/bmj.g1996.

9. Kroll DS, Nieva HR, Barsky AJ, Linder JA. Benzodiazepines are prescribed more frequently to patients already at risk for benzodiazepine-related adverse events in primary care. J Gen Intern Med. 2016;31(9):1027-34. https://doi.org/10.1007/s11606-016-3740-0.

10. Moore N, Pariente A, Bégaud B. Why are benzodiazepines not yet controlled substances? JAMA Psychiatry. 2015;72(2):110-1. https://doi.org/10.1001/jamapsychiatry.2014.2190.

11. Prescribing drugs of dependence in. general practice, Part B - Benzodiazepines. Melbourne: The Royal Australian College of General Practitioners; 2015.

12. World Health Organization. The ICD-10 Classification of Mental and Behavioural Disorders. Clinical Descriptions and Diagnostic Guidelines. Geneva: Divison of Mental Health, WHO; 2013. Https://doi.org/10.410.

13. Baldwin DS, Aitchison K, Bateson A, et al. Benzodiazepines: risks and benefits. A reconsideration. J Psychopharmacol. 2013;27(11):967-71.

14. Schutte-Rodin S, Broch L, Buysse D, Dorsey C, Sateia M. Clinical guideline for the evaluation and management of chronic insomnia in adults. J Clin Sleep Med. 2008 Oct 15;4(5):487-504. PMID: 18853708; PMCID: PMC2576317.

15. Committee on the Review of Medicines. Systematic review of the benzodiazepines: Guidelines for data sheets on diazepam, chlordiazepoxide, medazepam, clorazepate, lorazepam, oxazepam, temazepam, triazolam, nitrazepam, and flurazepam committee on the review of medicines. BMJ. 1980;280(6218):910-2. https://doi.org/10.1136/bmj.280.6218.910.

16. Truter I, Wiseman I, Kotze T,. Van W. (1996). The defined daily dose as a measure of drug consumption in south africa: a preliminary study. South African Medical Journal, 86(6), 675-579. Retrieved from https://www.researchgate.net/publication/14439148.

17. Institute for Public Health. (2015). National Health and Morbidity Survey 2015 (NHMS 2015). Non-Communicable Diseases, Risk Factors \& Other Health Problems (Vol. 2).

18. Pharmaceutical Services Division. (2015). Malaysian Statistics on Medicines 2011-2014.

19. Islam MM, Conigrave KM, Day CA, Nguyen Y, Haber PS. Twenty-year trends in benzodiazepine dispensing in the Australian population. Intern Med J. 2014;44(1):57-64. https://doi.org/10.1111/imj.12315.

20. Islam M, Mofizul, Wollersheim D. A comparison of opioids and benzodiazepines dispensing in australia. PLoS ONE. 2019;14(8):e0221438. https://doi.org/10.1371/journal.pone.0221438.

21. Finnish Medicines Agency Fimea and Social Insurance Institution. (2016). Finnish statistics on medicines 2016. Helsinki. Retrieved from http://www.julkari.fi/bitstream/handle/.

22. Shinfuku N, Tan $\mathrm{CH}$. Pharmacotherapy for schizophrenic inpatients in East Asia - Changes and challenges. Int Rev Psychiatry. 2008;20(5):460-8. https://doi.org/10.1080/09540260802397560.

23. Tor, P.-C., Ng, T. P., Yong, K.-H., Sim, K., Xiang, Y.-T., Wang, C.-Y., ... Baldessarini,R. J. (2011). Adjunctive benzodiazepine treatment of hospitalized schizophrenia patients in Asia from 2001 to 2008. International Journal of Neuropsychopharmacology, 14(6), 735-745. https://doi.org/10.1017/S146114571000163X.

24. Xiang, Y. T., Dickerson, F., Kreyenbuhl, J., Ungvari, G. S., Wang, C. Y., Si, T. M.,... Shinfuku, N. (2012). Adjunctive mood stabilizer and benzodiazepine use in older Asian patients with schizophrenia, 2001-2009. Pharmacopsychiatry, 45(6), 217-222. https://doi.org/10.1055/s-0031-1301292.

25. Xiang YT, Weng YZ, Leung CM, Tang WK, Ungvari GS. Clinical and social determinants of long-term use of benzodiazepines and its impact on quality of life of Chinese schizophrenia patients. Pharmacopsychiatry. 2007;40(6):269-74. Https://doi.org/10.1055/s-2007-992143. 
26. Nomura K, Nakao M, Sato M, Yano E. The long-term prescription of benzodiazepines, psychotropic agents, to the elderly at a university hospital in Japan. Tohoku J Exp Med. 2007;212(3):239-46. https://doi.org/10.1620/tjem.212.239.

27. Tan CH, Shinfuku N, Sim K. Psychotropic prescription practices in east Asia: Looking back and peering ahead. Curr Opin Psychiatry. 2008;21(6):645-50. https://doi.org/10.1097/YC0.0b013e32830e6dc4.

28. Grover S, Avasthi A, Kumar V, Kulhara P. An audit of first prescription of new patients attending a psychiatry walk-in-clinic in north India. Indian J Pharmacol. 2012;44(3):319. https://doi.org/10.4103/0253-7613.96302.

29. Kaufmann CN, Spira AP, Alexander GC, Rutkow L, Mojtabai R. Trends in prescribing of sedative-hypnotic medications in the USA: 1993-2010. Pharmacoepidemiol Drug Saf. 2016;25(6):637-45. https://doi.org/10.1002/pds.3951.

30. Tu K, Mamdani MM, Hux JE, Tu JB. Progressive trends in the prevalence of benzodiazepine prescribing in older people in Ontario, Canada. J Am Geriatr Soc. 2001;49(10):1341-5. https://doi.org/10.1046/j.1532-5415.2001.49262.x.

31. Cunningham CM, Hanley GE, Morgan S. Patterns in the use of benzodiazepines in British Columbia: Examining the impact of increasing research and guideline cautions against long-term use. Health Policy. 2010;97(2-3):122-9.

https://doi.org/10.1016/j.healthpol.2010.03.008.

32. Olfson M, King M, Schoenbaum M. Benzodiazepine use in the United States. JAMA Psychiatry. 2015;72(2):136-42. https://doi.org/10.1001/jamapsychiatry.2014.1763.

33. Petitjean S, Ladewig D, Meier CR, Amrein R, Wiesbeck GA. Benzodiazepine prescribing to the Swiss adult population: results from a national survey of community pharmacies. Int Clin Psychopharmacol. 2007;22(5):292-8.

https://doi.org/10.1097/YIC.0b013e328105e0f2.

34. Rosman S, Le Vaillant M, Pelletier-Fleury N. Gaining insight into benzodiazepine prescribing in General Practice in France: a data-based study. BMC Fam Pract. 2011;12(1):28. https://doi.org/10.1186/1471-2296-12-28.

35. Mcelroy J, Armstrong C. (2014). Despite risks, benzodiazepine use highest in older people. NIMH Press Office, 64-66. Retrieved from http://www.nimh.nih.gov/news/science-news/2014/despite-risks-benzodiazepine-use-highest-in-olderpeople.shtml.

36. Sundaran, S., Suresh, K., George, N., Baiju, D., Babu, G., Gopalakrishnan, A., ... Sundaran Professor, S. (2019). A study on the prescribing pattern of benzodiazepines in a tertiary care hospital: An observational study. World Journal of Pharmaceutical Research, 8(9), 438-444. https://doi.org/10.20959/wjpr20199-15438.

37. Ramadan W, El Khoury G, Deeb ME, Sheikh-taha M. Prescription patterns of benzodiazepines in the lebanese adult population: A cross-sectional study. Neuropsychiatr Dis Treat. 2016;12:2299-305.

https://doi.org/http://dx.doi.org/10.2147/NDT.S113078.

38. Ministry of Health Malaysia. (2009). Clinical Practice Guidelines: Management of Dementia (2nd Edition) (Second Edi). Putrajaya. Retrieved from http://www.moh.gov.my/moh/attachments/4484.pdf.

39. Ashton H. The diagnosis and management of benzodiazepine dependence. Curr Opin Psychiatry. 2005;18(3):249-55. https://doi.org/10.1097/01.yco.0000165594.60434.84.

40. Brett J, Murnion B. (2015). Management of benzodiazepine misuse and dependence. Australian Prescriber, 38(5). https://doi.org/10.18773/austprescr.2015.055.

41. Maric, N. P., Latas, M., Andric Petrovic, S., Soldatovic, I., Arsova, S., Crnkovic,D., ... Zikic, O. (2017). Prescribing practices in Southeastern Europe - focus on benzodiazepine prescription at discharge from nine university psychiatric hospitals. Psychiatry Research, 258, 59-65. https://doi.org/10.1016/j.psychres.2017.09.059.

42. Park SY, Bae SJ, Shin J-Y. Real-world prescribing patterns of long-acting benzodiazepines for elderly Koreans in 2013 . Int J Clin Pharmacol Ther. 2017;55(06):472-9. https://doi.org/10.5414/CP202974.

43. Tjagvad C, Clausen T, Handal M, Skurtveit S. Benzodiazepine prescription for patients in treatment for drug use disorders: $A$ nationwide cohort study in Denmark, 2000-2010. BMC Psychiatry. 2016;16(1):1-12. https://doi.org/10.1186/s12888-0160881-y.

44. Bushnell GA, Stürmer T, Gaynes BN, Pate V, Miller M. (2017). simultaneous antidepressant and benzodiazepine new use and subsequent long-term benzodiazepine use in adults with depression, United States, 2001-2014. JAMA Psychiatry, 
74(7), 747-55.

https://doi.org/10.1001/jamapsychiatry.2017.127310024/135599/Suomen_lääketilasto_2016_korjattu_2_painos.pdf? Sequence $=7$ \&isallowed $=y$.

45. Jessell L, Stanhope V, Manuel JI, Mateu-Gelabert P. (2020). Factors associated with benzodiazepine prescribing in community mental health settings. Journal of Substance Abuse Treatment, 109 (October 2019), 56-60.

https://doi.org/10.1016/j.jsat.2019.10.001.

\section{Figures}

\section{Amount of drug dispensed in 1 year (mg)}

\section{$\mathrm{DDD}$ (mg) x 365 (days) x No. of patients}

\section{1000}

\section{Figure 1}

The Defined Daily Dose Per 1000 Patients Per Day (16).

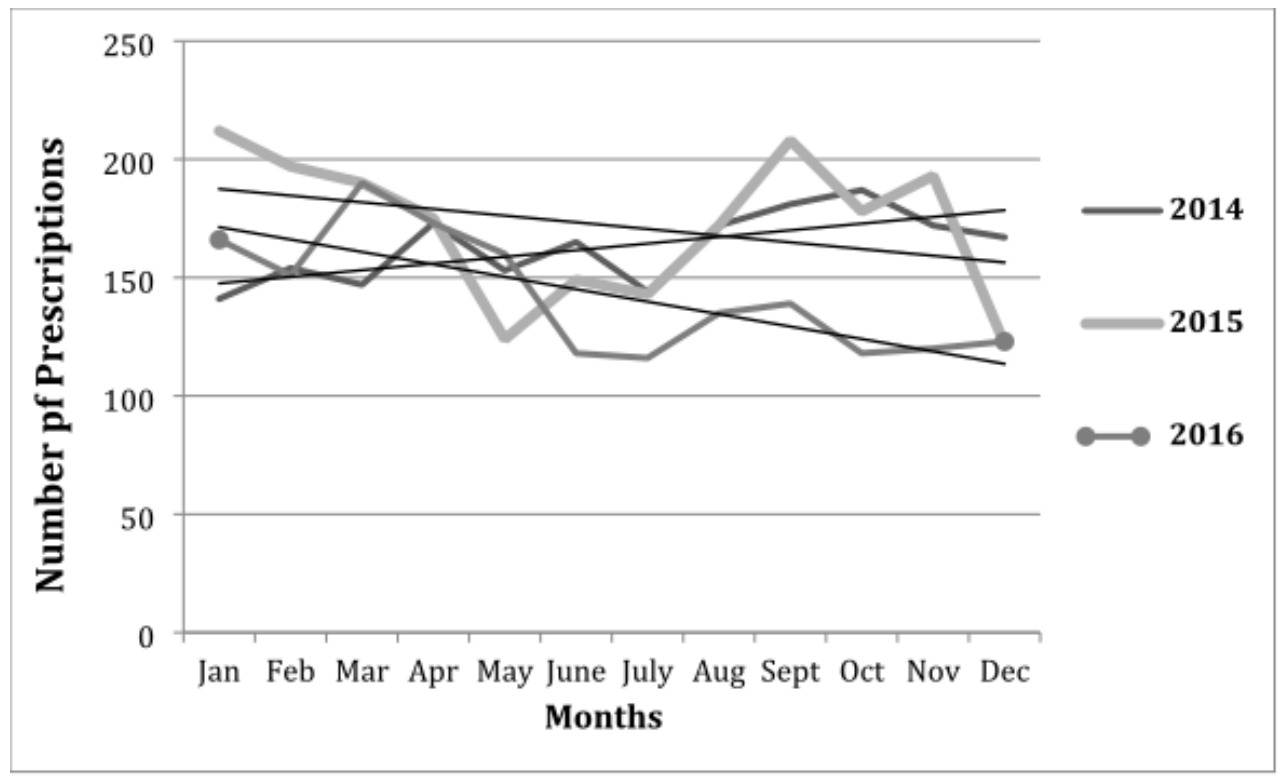

\section{Figure 2}

The Prescribing Trends of Benzodiazepines Based on Number of Prescriptions 